\title{
Inhibition of arterial thrombus formation by blocking exposed collagen surface using LWWNSYY-poly (L-glutamic acid) nanoconjugate
}

Na Sun ${ }^{a \#}$, Zhao Ye ${ }^{a \#}$, Tanyi Hao ${ }^{a}$, Si Zheng ${ }^{a}$, Yan Sun ${ }^{a}$, Youcai Zhang ${ }^{b *}$, Lin Zhang ${ }^{a *}$

a Department of Biochemical Engineering and Key Laboratory of Systems Bioengineering of the Ministry of Education, School of Chemical Engineering and Technology, Tianjin University, Tianjin 300350, People's Republic of China

${ }^{b}$ School of Pharmaceutical Science and Technology, Tianjin University, Tianjin 300072, People's Republic of China

\section{Corresponding Author}

*Tel: +86 22 27403389. Fax: +86 22 27403389. E-mail: youcai.zhang@tju.edu.cn (Y. Zhang); linzhang@tju.edu.cn (L. Zhang). 


\section{S1. Standard curve of LWWNSYY}

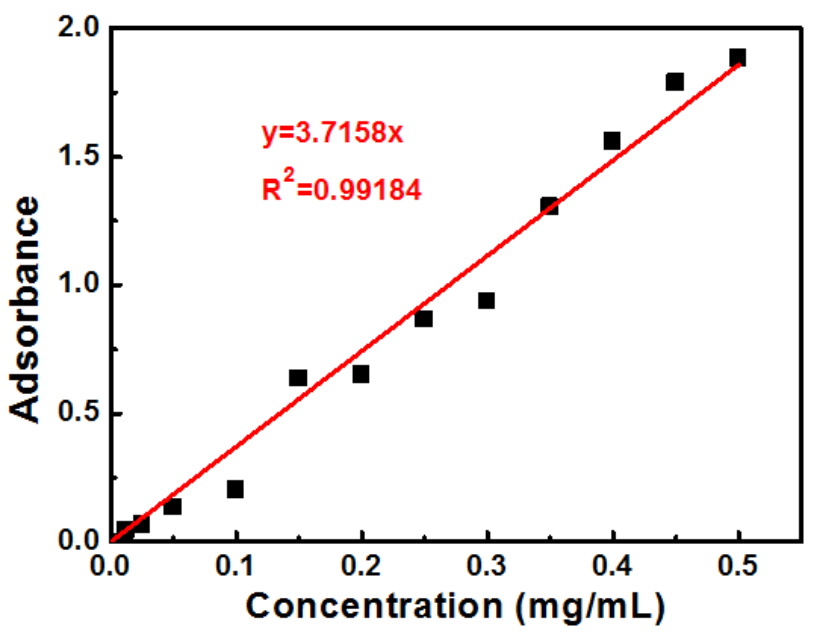

Figure S1. Standard curve of LWWNSYY using the absorbance at $280 \mathrm{~nm}$. The linear fitting is shown in red.

\section{S2. DLS result of L7-PGA}

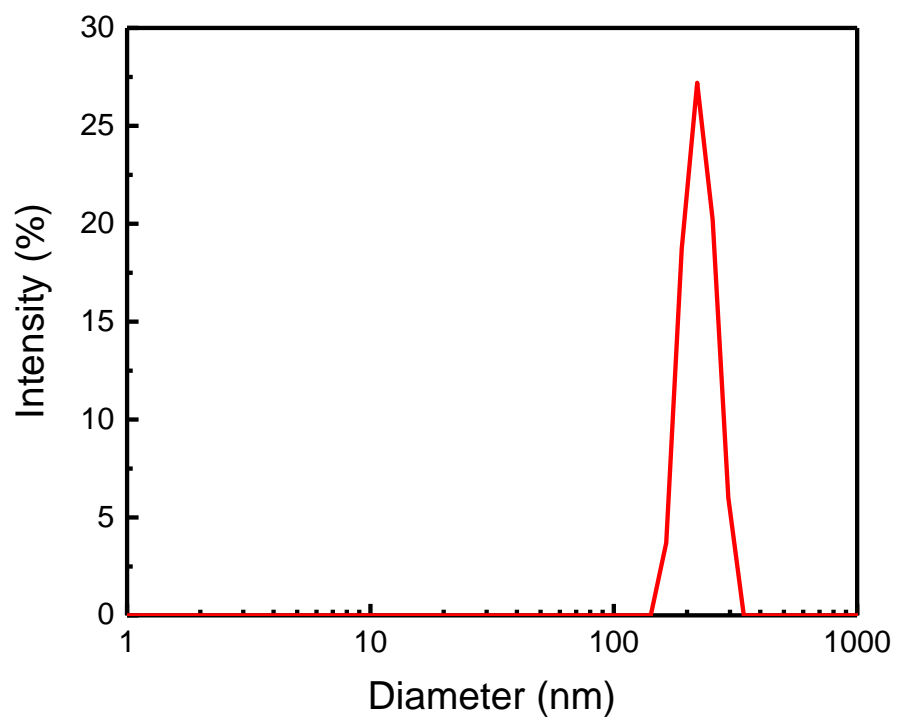

Figure S2. DLS result of L7-PGA.

\section{S3. Toxicity Assay of Inhibitors}

Twenty specific pathogen free (SPF) ICR mice weighing about 18-22 g (Vital River 
Laboratory Animal Technology Co. Ltd., Beijing, China) were randomly divided into four groups $(\mathrm{N}=5)$ and maintained (males and females were maintained separately) under standard conditions (temperature: $20-25^{\circ} \mathrm{C}$, relative humidity: 40-60\%) with food ad libitum. Quarantine and domesticate the mice for 2 days, to make them adapt to the new environment and remove unhealthy animals. $12 \mathrm{~h}$ before toxicity experiment, mice fasting.

Sixteen healthy mice were singled out and randomly divided into two groups $(\mathrm{N}=8$, half males and half females), and then treated with LWWNSYY or L7-PGA NPs (i.v., $3.75 \mathrm{mg} / 20$ $\mathrm{mL} / \mathrm{kg}$ ) to investigate their toxicity, respectively. After treatment, animals were maintained under standard conditions with food ad libitum and maintained in a $12 \mathrm{~h} / 12 \mathrm{~h}$ light/dark cycle at room temperature. Behavior, mortality and any other clinical signs of mice were observed and recorded for 7 days. The mice showed no abnormal clinical signs during the experiment, suggesting that both LWWNSYY and L7-PGA NPs had little toxicity at the dose of $3.75 \mathrm{mg} / \mathrm{kg}$. 